\title{
Talking Dollars in a Materials Science Sense
}

\section{Francine Garrone}

When Jennifer Byer dove head-first into a National Science Foundation (NSF)-sponsored project at Iowa State University, she knew that working on the Materials World Network project to investigate the Mixed Glass Former Effect in the $\mathrm{Na}_{2} \mathrm{O}+\mathrm{B}_{2} \mathrm{O}_{3}+\mathrm{P}_{2} \mathrm{O}_{5}$ Glass System depended on government funding. The project, which supports four students and connects six universities across the globe, is now slated for just one more year of funding. Byer, a senior materials engineering student, said additional support would be a good governmental investment in the future. Without the project, she said, she would have never gained the valuable research and materials engineering experience she needs to excel in her career. "New technologies are simply not developed in a year's worth of time," she said. "Personally, I know many students who would not have research positions or even full-time jobs without support from NSF, the U.S. Department of Energy (DOE), or the National Highway Institute (NHI)."

To encourage continued science and technology investment, Byer was just one of nearly 60 students, faculty members, and industry professionals who attended the annual Congressional Visits Day (CVD) activities March 30-April 1 in Washington, D.C. The event is organized by the Federation of Materials Societies and allows for materials science and engineering students and professionals to voice their support of an issue that directly affects them-better financial support for research in the United States.

"I wanted to be a positive force in making sure that engineering and science education and research will continue to be funded," said Laura Patrick, a materials science and engineering major at Virginia Polytechnic Institute and State University. More important to Patrick was letting Congressional leaders know the importance of funding for returning students. "I am non-traditional in that I did not attend college right after I left high school," she said. "Obtaining my degree would not be possible without the funding for engineering research and education, so I wanted to be sure and let Congress know that adult students are very dependent on

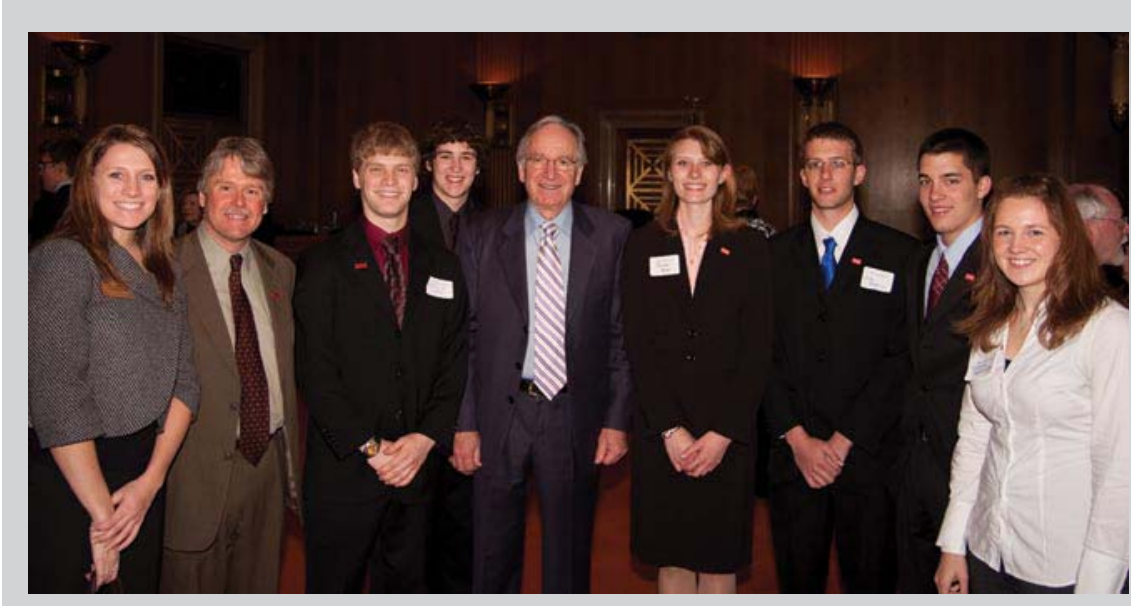

lowa State University representatives gather with lowa State Senator Tom Harkin (center) following a breakfast event. From left: Alyssa Staley, former director of lowa State University's Ambassadors; Iver Anderson, adjunct professor in the materials science and engineering department; and students Nathaniel Oster, Tim Pearson, Jennifer Byer, Greg Vetterick, Kevin Severs, and Sasha Kemmet. the funds that they vote on."

"Our most important priority was stressing the importance of fully appropriating funding to science-related programs for the next fiscal year," said Joe Corry, a materials science and engineering major at Rutgers. "This is particularly important for those of us who will pursue education past an undergraduate degree, since chances are a graduate project will be funded by grants from one of these government agencies."

As part of this year's activities, TMS members and students from the Material Advantage program stopped in at the offices of Congressional leaders to encourage them to support strong increases in funding for science agencies like NSF, the DOE Office of Science, and the National Institute of Standards and Technology. In addition, presentations were given by officials from various science-based offices. Jeremiah Abiade, assistant professor in the departments of materials science and engineering and mechanical engineering at Virginia Tech and director of the university's Laboratory for Oxide Research and Education, said the presentation by Kei Koizumi, assistant director for federal research and development at the White House Office of Science and Technology Policy gave the students a better understanding of the current economic situation and how innovations in research may be a means to help the nation recover. (Be sure to read the related article, "President Obama Hopes to Double Science Funding," in the News \& Update section).

"I think it is important that members of Congress see the students that are being affected by their policy decisions," Abiade said. "This event really emphasizes the need for increased service and outreach by all of us."

Francine Garrone is news editor for JOM. 